This was a retrospective study based on the data of births collected by Croatian Institute of Public Health for the year 2018. The study included a total of 2233 children born before week 37 of gestational age, 181 of which were conceived through ART. The prevalence of pathological conditions during pregnancy, delivery, and at birth, known as neurodevelopmental risk factors, was compared between children conceived through ART and those conceived naturally. The Mann-Whitney $U$ test was used to perform data analysis.

Pathological conditions in pregnancy were recorded in $82.3 \%$ of children conceived by ART, compared to $58.4 \%$ of children conceived naturally $(\mathrm{p}<0.001)$. The most common disorders during pregnancy are twin pregnancy $(2.8 \%)$, chorioamnionitis $(2.8 \%)$, and retarded fetal growth $(2.8 \%)$. On the other hand, in the group of naturally conceived neonates, the most common diagnoses were retarded fetal growth $(3.5 \%)$ and gestational diabetes (3.0\%).

It was observed that the share of children with pathological conditions was significantly higher in the group of those conceived by ART (92.2\%) compared to the second group $(84.1 \%)$ of children $(\mathrm{p}=0.003)$. The diagnoses that predominated among the ART conceived after delivery were neonatal respiratory arrest (24.9\%) and low birth weight (14.9\%). Additionally, the mean birth weight was significantly lower in the group of children conceived by ART (2170.77 grams), in comparison to another group (2307.68 grams, $\mathrm{p}=0.015)$. Nevertheless, groups of neonates did not differ significantly in postnatal mortality $(\mathrm{p}=1.00)$.

Newborns conceived by ART are more likely to suffer from conditions that represent risk for factors for neurodevelopmental disorders. Neonatal respiratory arrest especially represents the risk for the neurodevelopmental disorders. The results of this research are consistent with other published studies, further research is needed to assess other risk factors associated with ART.

\section{PERIOD OF PURPLE CRYING PROGRAM FOR THE PREVENTION OF ABUSIVE HEAD TRAUMA/SHAKEN BABY SYNDROME}

Edmond Power*, Farhana Sharif. School of Medicine, University College Dublin

\subsection{6/archdischild-2021-europaediatrics.476}

To review instances of abusive head trauma in Ireland and the United Kingdom To discuss the benefits of the Period of Purple Crying program To begin the pathways to implement the Period of Purple Crying program in Ireland.

Research published since the beginning of the COVID-19 pandemic has shown a marked increase in the instances of abusive head trauma in the United Kingdom. While there are many contributing factors to abusive head trauma, in these cases one of the main precipitants was the enforced isolation during the pandemic. An educational program is needed now more than ever to highlight the drastic consequences of abusive head trauma in infants and educate parents on what level of crying is to be expected from infants.

Areas that have implemented the Period of Purple Crying program have seen a reduction in the numbers of abusive head traumas. Other benefits of the program included an increased awareness among parents of what to do when a baby is crying. Cost-of-illness analysis also shows that the implementation of a program can have massive cost-saving benefits.

Ireland does not currently have a preventative program for shaken baby syndrome. The National Healthy Childhood Programme includes child health screen and developmental surveillance and would be an ideal means by which to introduce the Period of Purple Crying program. This service provides for parent contact with healthcare professionals at least twenty-five times beginning in pregnancy and ending at the child's third birthday. More research is also needed regarding exact numbers of abusive head trauma in Ireland.

\section{TOXIC STRESS AND NEURODEVELOPMENTAL TRAJECTORIES - OPORTUNITY FOR INTERVENTION}

Vanja Slijepčević Saftićc. Child and Youth Protection Center of Zagreb

10.1136/archdischild-2021-europaediatrics.477

Objective The effects of negative environmental factors in childhood result in neuro-biological changes. Exposed to powerful, negative environment, lead to hyperactivation of the neurological, imune and endocrine system. This state is known as a toxic stress. Symptoms may frequently imitate ADHD and other neurodevelopmental disorders. Hyper-vigilance and dissociation, could be mistaken for inattention. Impulsivity might be brought on by a stress response.

Method The aim of this study was to estimate preliminary results of a multi-disciplinary (Pediatric neurologist, Social worker, Psychologist, Psychiatrist, Speech therapist and special need expert) clinical assessment of patient came to Child and Youth protection Center, Zagreb, Croatia, in case of adverse childhood experiences, acording ACEs (Adverse Childhood Experience score) $\geq 4$. From 2015 - 2021 in Child and Youth Protection Center Zagreb we prospectively observed 1954 children with $\geq 4$. We were looking for presence of minor neurological dysfunctions (gross motor function, mild dysfunction in posture, reflexes, coordination, fine manipulative ability, fine motor disfunction, dyskinesia and excessive associated movements). For those with ACES $\geq 4$, and neurodevelopmental delay, EEG was indicated. We also evaluated simptoms of impulsivity, hyperactivity, and an inability to focus.

Results Neglect, physical and emotional abuse and high conflict divorce are the most important adverse experiences resulting in deviations in neurodevelopment. Impulsive behaviour, and other form of ADHD 'like' variants are significantly more frequent (over 50\%) in children with history of toxic stress. Over $30 \%$ of patients with ACES $\geq 4$ showed non-specific changes in EEG. In case of foetal abuse (Neonatal Abstinence Syndrome) 19 percent showed cognitive impairment, over 50 percent symptoms from ADHD spectrum, 33 percent had speech problems, and over 60 percent had learning problems. Child faced with toxic stress are obese in more than 70 percent.

Early detection of adverse childhood experiences help us to start with early interventions in order to prevent short and long term consequences of Toxic stress. 